\title{
(6) OPEN ACCESS \\ Adolescent inpatient activity 1999-2010: analysis of English Hospital Episode Statistics data
}

\author{
Dougal S Hargreaves, ${ }^{1,2}$ Russell M Viner ${ }^{1}$
}

- Additional data are available in the online appendices. To view them please visit the journal online (http://dx.doi. org/10.1136/archdischild2013-305559).

${ }^{1}$ Department of General \& Adolescent Paediatrics, UCL Institute of Child Health, London, UK

${ }^{2}$ Division of General Pediatrics, Boston Children's Hospital/ Harvard Medical School, Boston, Massachusetts, USA

\section{Correspondence to} Dr Dougal S Hargreaves, Division of General Pediatrics, Boston Children's Hospital/ Harvard Medical School, 300 Longwood Avenue, Boston, MA 02115, USA:

dougal.hargreaves@ childrens.harvard.edu

Received 28 October 2013 Revised 8 April 2014 Accepted 9 April 2014 Published Online First 1 May 2014
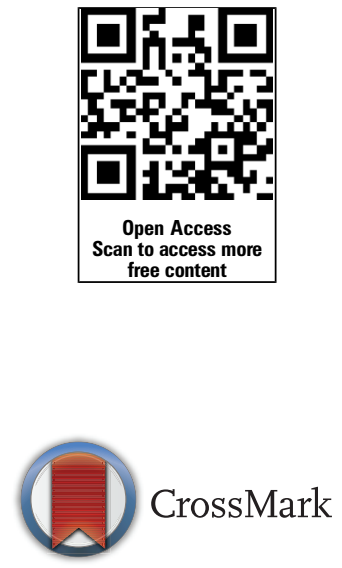

To cite: Hargreaves DS, Viner RM. Arch Dis Child 2014;99:830-833.

\section{ABSTRACT}

Objective To investigate patterns and trends of adolescent (10-19 years) inpatient activity in England by sex, disease category, and admitting speciality. Data 9632844 Finished Consultant Episodes (FCEs) from English patients aged 1-19 between 1999/2000 and 2010/2011 (Hospital Episode Statistics data). Analyses Age trends by sex and major International Classification of Disease 10 (ICD10) chapter; differences in activity rates by age and sex; inpatient activity trends over the past decade, disaggregated by sex, admitting speciality and ICD10 chapter.

Results Adolescent female patients account for more activity than girls aged 1-9 (139.4 vs 107.2 FCEs/ 1000). Female inpatient activity increases significantly between age 10 (70.9 FCEs/1000) and 19 (281.7 FCES/ 1000, of which non-obstetric care accounts for 155.9 FCEs/1000). Male activity increases much less during adolescence, with lower overall rates among adolescents than younger children (93.7 vs 142.9 FCEs/1000). Between 1999 and 2010, total adolescent inpatient activity increased faster among adolescents (10-19 years) $(+14.2 \%)$ than younger children ( $1-9$ years) $(+11.0 \%)$. Adolescent FCEs/1000 increased by $12.8 \%$, including higher rates admitted under Paediatrics $(+47.5 \%)$ and Paediatric Surgery (+23.2\%). Adolescents were admitted across a range of specialities.

Conclusions These data challenge the belief that adolescents are a healthy group who rarely use inpatient services. In England, use of inpatient services is higher among female patients aged 10-19 years than those aged 1-9 years, while adolescent activity has increased faster than for younger children over the past 11 years. Improving service quality for adolescents will require engagement of the many different teams that care for them.

\section{BACKGROUND}

Adolescent mortality (10-19 years) has overtaken deaths in any other period of childhood outside infancy in high, middle and some low income countries, ${ }^{1}$ and WHO has identified adolescent health as a global health priority. ${ }^{2} 3$ In high and low income countries, health services frequently fail to meet the distinct needs of adolescents, resulting in avoidable short and long term ill health. ${ }^{4-6}$ However, strategies to improve the quality of these services have often been limited by data availability, especially for healthcare activity. ${ }^{6-8}$ In a recent survey, Patton et $a l^{9}$ found that health service utilisation was one of only two adolescent health indicators for which no national data were readily available for any country.

In England, the Chief Medical Officer's (CMO) Annual Report $2012^{10}$ reported ongoing, outdated assumptions that adolescence is a healthy period of

\section{What is already known on this topic}

- Historically, adolescence has been seen as the healthiest time of life, with low rates of healthcare use.

- Adolescent mortality has fallen more slowly than in other age groups and is now higher than in earlier childhood outside infancy.

- Recent reports have identified better data on adolescent healthcare use as a key step to understanding their needs and improving outcomes.

\section{What this study adds.}

- Among female patients, inpatient activity levels are higher among adolescents than younger children (1-9 years).

- Inpatient activity has increased faster for adolescents than younger children over the past decade.

- Adolescents are admitted across a range of specialities, highlighting the need for organisations to identify clinicians with specific responsibility for adolescent health.

life, with little utilisation of health services. Analysis of health service use among adolescents was identified as an important research gap to challenge these assumptions and guide service planning and quality improvement. For example, young people aged 16-24 report the poorest NHS experience of any age group, ${ }^{11}$ and concerns have been raised about the quality and age appropriateness of many aspects of care for this group. ${ }^{5}$ In response, extensive policy recommendations have been made in recent years by a previous $\mathrm{CMO}$ annual report, ${ }^{12}$ and influential reports by Kennedy ${ }^{5}$ and the Children and Young People's Health Outcomes Forum (2012). ${ }^{7}$ Lack of data has consistently been identified as a key factor limiting service improvement and policy development in adolescent health.

We aim to address this lack of data by examining national adolescent inpatient activity from 1999 to 2010 in the English NHS. In this study, we investigate

1. age trends in inpatient activity, disaggregated by sex and disease category

2. the proportion of hospital activity accounted for by each speciality

3. time trends in activity by speciality and disease category. 


\section{METHODS}

Data

Anonymised, aggregated Hospital Episode Statistics (HES) data for England were supplied for the years 1999/2000 to 2010/ 2011 by Northgate Information Solutions (http://www. northgate-is.com/). Finished Consultant Episodes (FCEs), the standard HES unit of inpatient activity, were used throughout. This is defined as a 'continuous period of admitted patient care under one consultant within one healthcare provider' and is considered to provide the best overall measure of consultant workload and wider resource use. ${ }^{13}$

FCEs were analysed by single year of age, sex, International Classification of Disease 10 (ICD10) chapter and by admitting speciality. Patients with incomplete data were excluded. A total of 9632844 FCEs were analysed.

We limited our analyses to age 1-19 years, with 19 being the upper limit of the WHO definition of adolescence 10-19 and the National Service Framework for Children and Young People in England. Data from infants were excluded due to problems excluding birth episodes in HES data for infants, and for consistency with other comparisons of child and adolescent health.

\section{Analysis}

We calculated the number of inpatient episodes per thousand age-specific population by age and sex, using mid-year population estimates for the years 1999-2010 from the Office of National Statistics (http://www.ons.gov.uk). We also compared overall activity levels in adolescence (10-19 years) versus earlier childhood (1-9 years).

We then disaggregated activity into seven major ICD10 categories. Five common ICD10 chapters were used that account for a large proportion of activity (Infection, Respiratory, Digestive, Pregnancy/Childbirth-related, Injury/Poisoning). Chapter XVIII (Symptoms, Signs and Abnormal Clinical and Laboratory Findings) and Chapter XXI (Factors Influencing Health Status and Contact with Health Services) were combined into a category labelled 'Non-specific'. All other activity was labelled as 'Other'.

We calculated trends in overall activity between 1999/2000 and 2010/2011 using these major categories, and also using single ICD10 chapters. Similarly, we disaggregated inpatient activity by admitting speciality and calculated the change between 1999/2000 and 2010/2011.

\section{RESULTS}

Figure 1 shows age trends for England in 2010/2011 for overall inpatient activity and activity by major ICD10 chapters in male and female patients. FCEs per thousand population are higher in male than female patients throughout early life but this relationship is progressively reversed from the age of 14 onwards.

Among young women, FCEs per thousand increase almost fourfold during adolescence, from 70.9 aged 10 to 281.7 aged 19. Much of this increase is accounted for by obstetric admissions, which increase rapidly from age 15 onwards, contributing $44.7 \%$ of FCEs by age 19 years. However, non-obstetric activity also more than doubles, from 70.9 to $155.9 \mathrm{FCEs} / 1000$ per year. There are increases in all ICD10 chapters shown, including an increase of $123 \%$ in injury episodes ( 8.0 vs 17.9 FCEs/1000) and an $80 \%$ increase in digestive episodes (11.2 vs $20.2 \mathrm{FCEs} / 1000)$.

Among young men, a much smaller increase occurs between the ages of 10 and 19: from 84.6 to $104.5 \mathrm{FCEs} / 1000$. The majority of this change is explained by injuries, which increase from 12.5 to 27.4 FCEs/1000.
In 2010/11, adolescents accounted for 731780 FCEs (117.1/ 1000), while children aged 1-9 were responsible for 701563 FCEs (127.7/1000). Since 1999, adolescent FCEs increased by $14.2 \%$ whereas the increase among children aged 1-9 was $11.0 \%$. This largely reflects demographic changes: the activity rates per thousand age-specific population increased by $12.8 \%$ for adolescents and $14.1 \%$ for younger children.

As seen in figure 1, the age trends differ between male and female patients. Adolescent activity for male patients is lower than for younger children (93.7 vs 142.9 FCEs/1000), while the reverse is seen for female patients (139.4 vs 107.2 FCEs/1000).

Between 1999/2000 and 2009/10, FCEs/1000 in male patients increased by $13.0 \%$. The largest increase was for digestive episodes $(+39.8 \%)$, while injury episodes decreased by $1.7 \%$. Female activity also increased by $13.0 \%$ overall, with a $25.1 \%$ increase in non-obstetric activity offset by a $13.3 \%$ reduction in obstetric episodes. The largest increases were seen for digestive episodes $(+48.0 \%)$ and injuries $(+25.2 \%)$. Full details of inpatient activity and trends by ICD10 chapter are presented in figure 2 and online supplementary appendices A, B.

Figure 3 presents adolescent inpatient activity for England by selected admitting specialities in 2010/2011. Paediatrics was the largest single speciality, with $20.2 \%$ of activity, compared with $18.2 \%$ for Obstetrics/Gynaecology. However, 35.3\% was accounted for by the surgical specialities combined (Paediatric Surgery, General Surgery, Orthopaedics, ENT, Plastics, Oral \& Dental).

Over the 11-year period, FCEs/1000 increased in the majority of major specialities, including Paediatrics (+47.5\%), Accident $\&$ Emergency (+317.0\%), General Medicine (+15.0\%), Paediatric Surgery $(+23.2 \%)$. There were decreases in Obstetrics/Gynaecology/Midwifery (-12.0\%), General Surgery $(-5.0 \%)$, Orthopaedics (-6.9\%), ENT $(-22.3 \%)$, and Child and Adolescent Mental Health Services/Learning Disability $(-38.0 \%)$ (see online supplementary appendix C).

\section{DISCUSSION}

Use of inpatient services by female patients is higher in adolescence than earlier childhood (1-9 years), while the reverse is true for male patients. Over the last decade, adolescent activity in England has increased faster than activity for younger children. Inpatient activity increases significantly over the second decade of life, particularly for female patients, whose standardised activity rates are almost four times higher aged 19 than aged 10. Although much of this increase is accounted for by obstetric care, inpatient episodes for digestive and respiratory disorders also approximately double over this period.

The observation that female inpatient activity is higher than in early childhood is a reversal of historical hospital trends. For much of the twentieth century, high infectious disease burden drove high early childhood morbidity and mortality, with survivors often enduring prolonged hospital admissions. ${ }^{14}$ However, our finding is consistent with recent reports that the epidemiological transition has resulted in changes to historic mortality relationships across the early life course, with mortality among patients aged 10-19 years now greater than that among patients aged 1-4 years in most upper and middle income countries. ${ }^{1}$

\section{Strengths and limitations}

A strength of this study is the use of comprehensive, nationallevel data, collected in a consistent way over several years. The data include all inpatient care (including psychiatric care) that is delivered in NHS hospitals or commissioned by the NHS from 
Figure 1 Inpatient activity by age and sex, England, 2010/2011. (A) Age standardised inpatient activity by age and sex. (B) Male inpatient activity by age and disease category. (C) Female inpatient activity by age and disease category.
A

Inpatient activity by age and sex, England, 2010/11

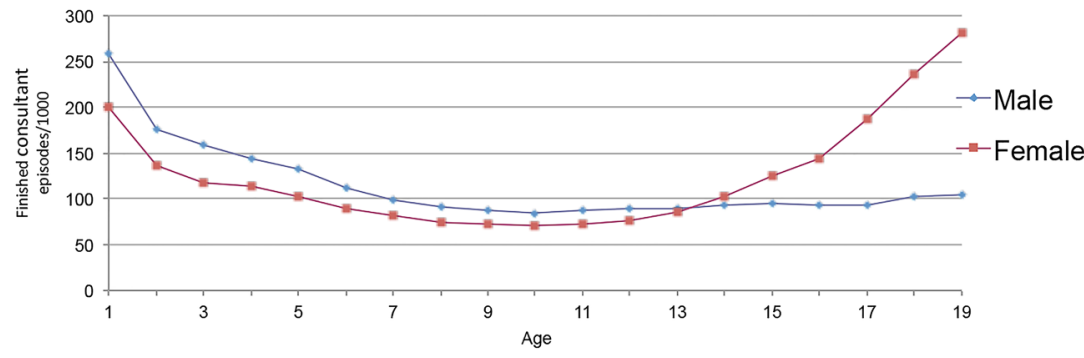

Male inpatient activity by age, England, 2010/11

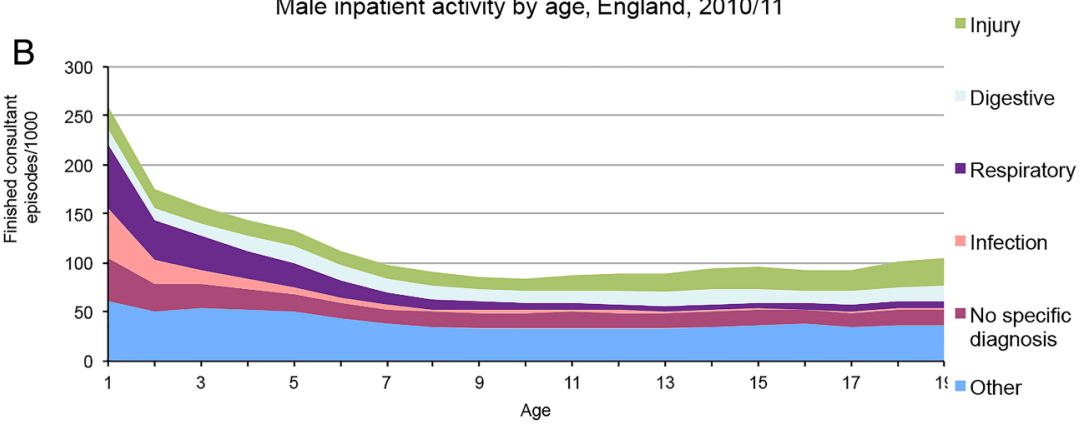

Female inpatient activity by age, England, 2010/11

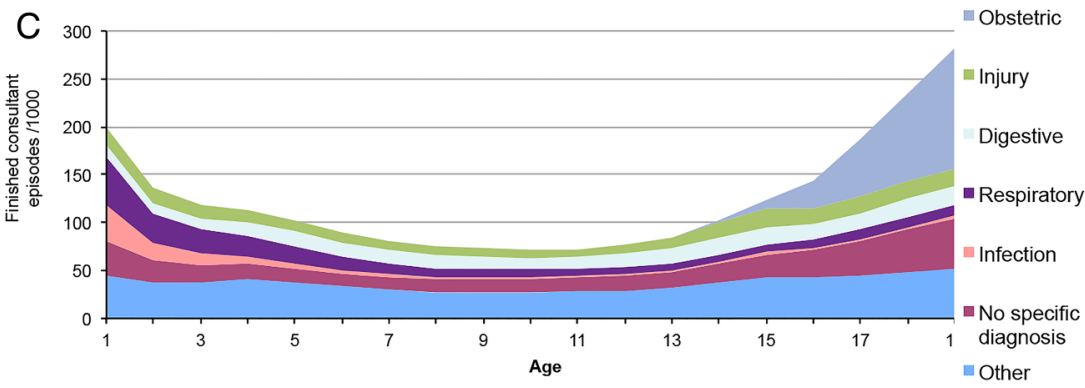

the private sector, although the small amount of privately funded care in non-NHS hospitals is excluded. ${ }^{13}$

The quality of HES data is a potential weakness, with previous authors reporting that diagnostic coding is sometimes inconsistent or inaccurate. ${ }^{15}$ We have mitigated these concerns when possible: inpatient data are known to be more reliable than other sources, such as Emergency Department data, ${ }^{15}$ and ICD10 chapter is likely to be more reliable than exact diagnosis.

A further limitation is that we restricted analyses to FCEs and to the WHO definition of adolescence as 10-19 years. Analysis of bed days, length of stay and total discharges would give a more complete picture of adolescent inpatient activity, and would be needed to investigate cost trends. However, inpatient length of stay is known to be higher among adolescents than in childhood after infancy, ${ }^{10}$ so analysis of these indicators would probably find an even greater proportion of care accounted for by adolescents. Similarly, some authors have used the broader age range of 10-24 to encompass adolescence and young adulthood. ${ }^{18}$ These merit further research but were beyond the scope of the current study.

\section{Implications}

Although inpatient care represents a small proportion of healthcare delivered to adolescents, avoiding unnecessary hospital admission has been identified as a key health priority by young people themselves, ${ }^{16}$ and high-quality inpatient care is critical to
Figure 2 Adolescent inpatient episodes in England (1999/2000-2010/ 2011).

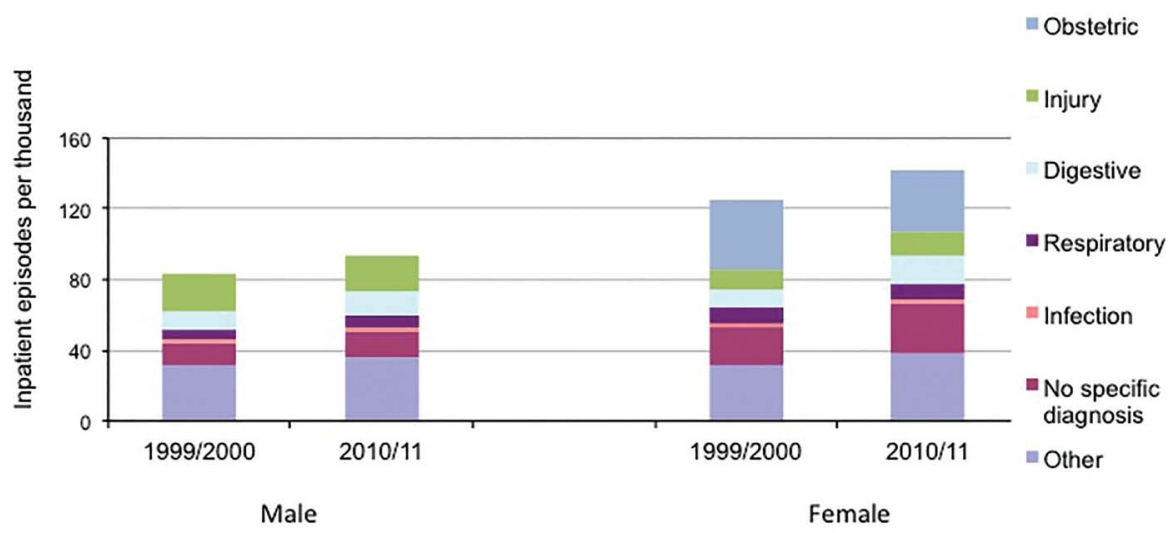




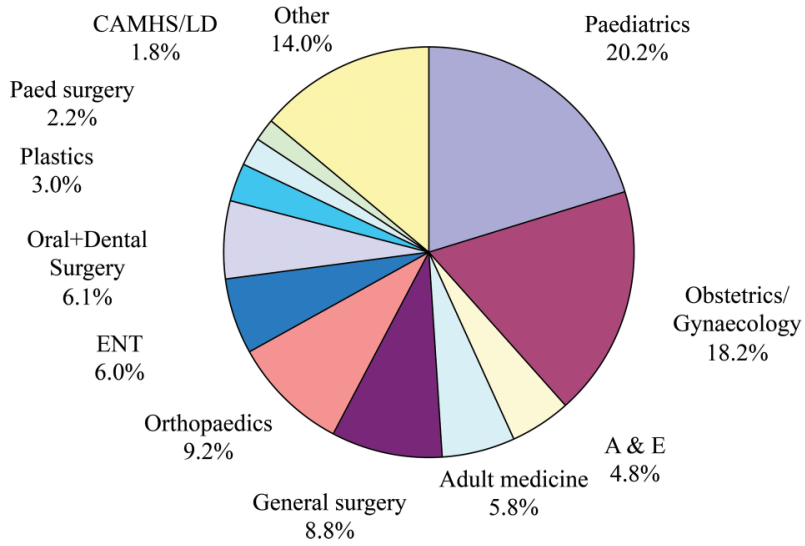

Figure 3 Adolescent inpatient activity by admitting speciality, England, 2010/2011. CAMHS/LD, Child and Adolescent Mental Health Services/Learning Disability.

improving global outcomes from many key causes of adolescent mortality and morbidity, including trauma, obstetric and psychiatric emergencies. ${ }^{17} 18$

Influential reports have consistently identified two key barriers to improving health services for young people: first, lack of understanding of adolescent health needs, including outdated perceptions that adolescence is a healthy time of life with little use of health services; second, lack of age-specific data to inform service planning, quality improvement and economic

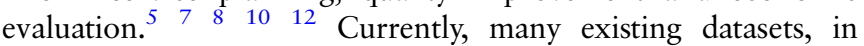
England and internationally, report healthcare utilisation only in broad age bands (eg, 5-14, 15-44), preventing service leaders or national policy makers from seeing what proportion of their work and resources is accounted for by adolescents. ${ }^{7} 9$ For example, US data show that children aged 17 or under account for $16 \%$ of all hospitalisations, costing a total of $\$ 33.6$ billion in $2009 .{ }^{19}$ No data are publicly available for the age range $10-19$ and the majority of cost and diagnostic information is aggregated across ages $0-17$.

Our data directly address the first issue, showing that adolescents account for a large and increasing amount of inpatient activity, spread across many specialities. These results also contribute to the growing base of age-specific data that is available to researchers and decision makers. Following the government commitment to publish health data in 5-year bands wherever possible, provisional adolescent-specific diagnostic data have recently been published for the first time, ${ }^{20}$ and our findings may provide useful information for benchmarking and to place these data in a wider context. The You're Welcome standards ${ }^{2}$ were developed to be applicable to all services seeing adolescent patients $^{21}$ and have been validated for use across all inpatient settings. $^{22}$ It is hoped that greater awareness of adolescent patients may increase the use of You're Welcome standards, particularly outside paediatric settings. Used in conjunction with cost data, our findings may also inform economic evaluations of adolescent services, as advocated in the CMO 2012 report. ${ }^{10}$

Lastly, while previous efforts to improve adolescent services have often been initiated by staff working in paediatrics, adult medicine or another single speciality, ${ }^{82} 23$ our data highlight the large number of specialities responsible for delivering adolescent care. Future work to improve the quality of adolescent inpatient services should emphasise cooperation and team working between all relevant specialities, under the leadership of an adolescent physician or other individual with responsibility for all adolescent health issues within an organisation.

Contributors Both authors contributed to planning and writing the article. DSH did the analyses and is the guarantor.

Funding Support for this research was provided by the Commonwealth Fund. The views presented here are those of the authors and should not be attributed to the Commonwealth Fund or its directors, officers or staff.

\section{Competing interests None.}

Provenance and peer review Not commissioned; externally peer reviewed.

Open Access This is an Open Access article distributed in accordance with the Creative Commons Attribution Non Commercial (CC BY-NC 3.0) license, which permits others to distribute, remix, adapt, build upon this work non-commercially, and license their derivative works on different terms, provided the original work is properly cited and the use is non-commercial. See: http://creativecommons.org/ licenses/by-nc/3.0/

\section{REFERENCES}

1 Viner RM, Coffey C, Mathers C, et al. 50-year mortality trends in children and young people: a study of 50 low-income, middle-income, and high-income countries. Lancet 2011;377:1162-74.

2 Department of Health. You're Welcome-Quality criteria for young people friendly health services. London, 2011.

3 WHO. Adolescent friendly health services: an agenda for change. Geneva, 2002.

4 UNICEF. UNICEF state of the world's children 2011-adolescence: an age of opportunity. 2011.

5 Kennedy I. Getting it right for children and young people: overcoming cultural barriers in the NHS so as to meet their needs. 2010.

6 Lawrence RS, Appleton-Gootman J, Sim LJ. Adolescent health services: missing opportunities. Washington, DC: The National Academies Press, 2009.

7 Lewis I, Lenehan C. Report of the Children and Young People's Health Outcomes Forum. 2012.

8 Payne D. Meeting the needs of young people in hospital. Arch Dis Child 2013;98:930-2.

9 Patton GC, Coffey C, Cappa C, et al. Health of the world's adolescents: a synthesis of internationally comparable data. Lancet 2012;379:1665-75.

10 Davies SC. Annual report of the Chief Medical Officer 2012. Our children deserve better: prevention pays. 2012.

11 Hargreaves DS, Viner RM. Children's and young people's experience of the National Health Service in England: a review of national surveys 2001-2011. Arch Dis Child 2012;97:661-6.

12 Donaldson L. Under their skins: tackling the health of the teenage nation. Chief Medical Officer's Annual Report. 2007.

13 HES User Guide. http://www.hscic.gov.uk/hes (accessed 16 Apr 2014).

14 Stewart-Brown S, Waterston DT. Child public health. Oxford: Oxford University Press, 2010.

15 Gonzalez-Izquierdo A, Woodman J, Copley L, et al. Variation in recording of child maltreatment in administrative records of hospital admissions for injury in England, 1997-2009. Arch Dis Child 2010;95:918-25.

16 Adams L, Ahmad S, Bagnall J, et al. 'Nothing about us, without us?' Young people and the future of the NHS. 2011

17 Joshipura M. Global alliance for care of the injured. Inj Prev 2012;18:69.

18 Ronsmans C, Etard JF, Walraven G, et al. Maternal mortality and access to obstetric services in West Africa. Trop Med Int Health 2003;8:940-8.

19 Yu H, Wier LM, Elixhauser A. Hospital stays for children, 2009. H CUP/AHRQ, 2011. http://www.hcup-us.ahrq.gov/reports/statbriefs/sb118.pdf (accessed 16 Apr 2014)

20 Health and Social Care Information Centre. Children in hospital episode statistics July 2012 to June 2013, provisional. HSCIC, 2013. https://catalogue.ic.nhs.uk/ publications/hospital/monthly-hes/prov-mont-hes-admi-outp-ae-apr-jun-13-14/ prov-mont-hes-admi-outp-ae-apr-jun-13-14-toi-rep.pdf (accessed 16 Apr 2014).

21 Hargreaves DS. Revised You're Welcome criteria and future developments in adolescent healthcare. J Clin Res Pediatr Endocrinol 2011;3:43-50.

22 Hargreaves DS, McDonagh JE, Viner RM. Validation of You're Welcome quality criteria for adolescent health services using data from national inpatient surveys in England. J Adolesc Health 2013;52:50-57.e1.

23 Harden PN, Walsh G, Bandler N, et al. Bridging the gap: an integrated paediatric to adult clinical service for young adults with kidney failure. BMJ 2012;344:e3718. 